\title{
Visible-NIR reflectance spectroscopy as a potential tool for management of soil phosphorus fertility in legume-based pasture in New Zealand
}

\author{
K. KAWAMURA ${ }^{1}$, A.D. MACKAY ${ }^{2}$, M. TUOHY ${ }^{3}$, K. BETTERIDGE ${ }^{2}$ and I. D. SANCHES ${ }^{3}$ \\ ${ }^{1}$ National Institute for Agro-Environmental Sciences, 3-1-3 Kannondai, Tsukuba, Ibaraki 305-8604, Japan, \\ ${ }^{2}$ AgResearch, Grasslands Research Centre, Private Bag 11 008, Palmerston North \\ ${ }^{3}$ Center for Precision Agriculture, Institute Natural Resources, Massey University
} alec.mackay@agresearch.co.nz

\begin{abstract}
Increasing the current precision of nutrient management will need analytical tools that aid in collecting site specific data. A technology with potential is hyperspectral remote sensing. Modern, portable spectroradiometers permit reflectance data in the spectral region between 350 and $2500 \mathrm{~nm}$ to be collected quickly. With the limited sampling, handling, and processing required the technology also offers rapid turn around times, if calibrations can be developed. In this paper the findings of a pilot study examining the use of hyperspectral reflectance spectra of pasture to indirectly assess the phosphorus (P) status of the soil are presented and discussed. Spectral data were collected in spring 2004 and again in summer 2006 from a small area of each of 30 legume-based sheep grazed pasture plots that varied in soil P fertility (Olsen P 6-68 $\mu \mathrm{g} / \mathrm{ml}$ ). Significant $(\mathrm{P}<0.05)$ relationships were found with two commonly used vegetation indices and pasture $P$ content $\left(R^{2}>0.80\right)$. In an exploratory analysis using all the spectral waveband data, several paired-bands with high coefficients of determination $\left(\mathrm{R}^{2}\right)$ were detected for pasture $\mathrm{P}$ and $\mathrm{K}$ content, but not for pasture $\mathrm{N}$ content, pasture growth rate or pasture dry matter content. The differences detected in pasture $\mathrm{P}$ content were consistent with the differences in soil P fertility measured by the Olsen P soil test, as indicated by the relationship between pasture $\mathrm{P}$ content and soil Olsen P in both $2004\left(R^{2}=0.90\right)$ and $2006\left(R^{2}\right.$ $=0.86$ ). This pilot study needs to be broadened to examine other methodologies for interpreting the spectral data and extended to other pasture types and soil groups of varying soil fertility.
\end{abstract}

Keywords: Olsen P, soil fertility, remote sensing, hyperspectral imaging, spatial variability, soil phosphate, plant phosphate

\section{Introduction}

One of the major barriers to the greater use of spatial models and tools is the difficulty and cost associated with collecting site specific data (Betteridge et al. 2006). For example, increasing the current precision of nutrient management will require the collection of soil fertility data at the paddock rather than block level. This is neither practical nor cost effective using traditional soil testing methods. Similarly, using traditional approaches for establishing and managing the nutrient status of soil in and around waterways as part of an overall nutrient management package is also impractical, due to a need for extensive data sets to characterise the nutrient profiles across the landscape. Techniques that can measure soil nutrient status quickly and cost effectively and that are able to provide continuous data across the landscape need to be developed. One potential technology is objective classification through remote sensing that would allow the collection of continuous data across a landscape.

The use of satellite and land based remote sensors to aid nutrient planning is not a new concept (Vickery et al. 1980), but it is being used mainly for the detection of crop nutrient status. For example, the European Farmstar decision support tool for crop management utilises satellite imagery (Coquil \& Bordes 2005), while the land based sensors such as Yara N-sensor and GreenSeeker detect differential crop reflectance to determine nitrogen (N) status of a crop and are used to adjust the $\mathrm{N}$ application rate on-the-go (Bredemeier \& Schmidhalter 2005). On-the-go sensors for plant nutrients other than $\mathrm{N}$ and for soil characteristics are being developed (Sudholter et al. 2005; Lund et al. 2005), although little active work is being conducted on phosphorus $(\mathrm{P})$ in legume-based grazed pastures. Mutanga et al. (2004) have examined the use of remote sensing for assessing pasture quality, which included $\mathrm{P}$ content, for the management of Savanna rangelands. In this paper, the findings of a pilot study examining the use of hyperspectral reflectance spectra of pasture to indirectly assess the P status of the soil are presented and discussed. Data sets were collected over 2 years to examine reproducibility.

\section{Methods}

\section{Study site}

The study was carried out at AgResearch Ballantrae Hill Country Research Station utilising the 30 plots of a soil biodiversity study located on low-slope areas in low fertility and high fertility farmlets. The low fertility farmlet has a history of no fertiliser inputs since 1980, while the high fertility farmlet has a history of high superphosphate 
Table 1 Pasture and soil characteristics of the plots on the low-slope area of the low and high fertility farmlets.

\begin{tabular}{|c|c|c|}
\hline \multirow{2}{*}{ Parameter } & \multicolumn{2}{|c|}{ Range } \\
\hline & Low fertility plots & High fertility plots \\
\hline \multirow[t]{2}{*}{ Pasture type } & Browntop & Ryegrass \\
\hline & Suckling clover & White clover \\
\hline Grazing & Continuous sheep & Continuous sheep \\
\hline \multicolumn{3}{|c|}{ Pasture growth rate $(\mathrm{kg} \mathrm{DM} / \mathrm{ha} /$ day) } \\
\hline Spring 2004 & $16-91$ & $68-176$ \\
\hline \multicolumn{3}{|c|}{ Pasture dry matter content (\%) } \\
\hline Spring 2004 & $13-22$ & $13-18$ \\
\hline Pasture $\mathrm{P}$ content $(\mathrm{P} \%)$ & $0.15-0.22$ & $0.34-0.42$ \\
\hline Pasture $\mathrm{N}$ content (N\%) & $1.78-3.00$ & $2.60-3.50$ \\
\hline Pasture $\mathrm{K}$ content $(\mathrm{K} \%)$ & $1.5-2.3$ & $2.7-4.0$ \\
\hline \multicolumn{3}{|l|}{ Soil fertility (Autumn 2004) } \\
\hline Olsen $\mathrm{P}$ & $6-13$ & $22-68$ \\
\hline $\mathrm{pH}$ & $5.2-5.5$ & $5.2-5.5$ \\
\hline
\end{tabular}

fertiliser inputs dating back to 1975 (Mackay et al. 1999). At the low fertility sites, pastures are dominated by lowfertility brown top (Agrostis capillaris), suckling clover (Trifolium dubium) and broadleaf species, while at the high fertility site, pastures have $>40 \%$ perennial ryegrass (Lolium perenne) and white clover (Trifolium repens) is the dominant legume. As part of the biodiversity study, three treatments (Control, Herbicide, N inputs), replicated five times, were imposed at both sites. A summary of the soil and pasture data from the study area are in Table 1. Both sites have been continuously grazed by sheep since 1975.

\section{Canopy spectral measurements}

The spectral reflectance of the pasture was captured using a Field Spec ${ }^{\circledR}$ Pro, which has high resolution $(3-10 \mathrm{~nm})$ and a 350-2500 nm spectral range. Designed to collect solar reflectance, radiance and irradiance measurements, this hand-held instrument was particularly suited to this level of investigation. Spectra were collected in the spring (November) 2004 and in the summer (January) 2006. A single measurement (actually the average of 10 scans over all wavelengths in 1 second) was made at a height of approximately $50 \mathrm{~cm}$ above the ground on each of 15 low-slope plots on the low fertility farmlet and 15 lowslope plots on the high fertility farmlet in 2004. In 2006 this was extended to 10 measurements on the target area of each plot. Measurements were made between 11.00 am and $1.00 \mathrm{pm}$. Spectral areas which displayed high levels of atmospheric noise (1350-1410 nm, 1800-2000 $\mathrm{nm})$, due to reduced solar irradiance $(2215-2500 \mathrm{~nm})$ in regions of low signal-to-noise ratio, or displayed noise due to splicing between individual spectrometers in the instrument (350-380, 2215-2500 nm) (Analytical Spectral Devices Inc. 1997) were omitted from the data, resulting in a total of 1572 spectral bands.

Pasture dry matter content and pasture growth rates were measured on each plot at the same time as the spectral data were collected. The $\mathrm{P}, \mathrm{K}$ and $\mathrm{N}$ content of pasture at each site was measured on a pasture sample bulked within-plot from all the spring and summer pasture cuts in the biodiversity study in 2004/05 and $2005 / 06$ respectively. At the time of spectral sampling, the 2004 spring pastures were short and contained largely green leaf with the amount of dead matter $<5 \%$, while the 2006 summer pastures had higher standing masses and dead matter within the sward (13\%). Soil Olsen P was measured in autumn 2004 and autumn 2005.

\section{Evaluation and analysis}

The spectral data were evaluated in two separate analyses. 1. A number of vegetation indices (VI's) were calculated from the spectral data collected from all 30 plots in spring 2004 and regressed using a simple linear analysis against pasture $\mathrm{P}, \mathrm{K}$ and $\mathrm{N}$ content, dry matter content and growth rate. The indices examined included:

- Normalized Difference Vegetation Index (NDVI) (nirred)/(nir+red) $(750 \mathrm{~nm}-600 \mathrm{~nm}) /(750 \mathrm{~nm}+600 \mathrm{~nm})$ (Rouse et al. 1974)

- Normalized Difference Vegetation Index Red (NDVI Red) (nir-red)/(nir+red) (760:900-30:690)/ (760:900+630:690)

- Normalized Difference Vegetation Index Green (NDVI Green) (nir-green)/(nir+green) (760:900-545:565)/ (760:900+545:565) (Gitelson et al. 1996)

- Photochemical Reflectance Index (PRI) (531nm$570 \mathrm{~nm}) /(531 \mathrm{~nm}+570 \mathrm{~nm})$

- Soil Adjusted Vegetation Index (SAVI) $(1+\mathrm{L})($ nirred $) /($ nir + red $+\mathrm{L}) \quad(1+\mathrm{L})(760: 900-630: 690) /$ $(760: 900+630: 690+\mathrm{L}) \mathrm{L}=1.00$ bassa densità vegetazione $\mathrm{L}=0.50$ densità intermedia $\mathrm{L}=0.25$ elevata densità and Simple Ratio (SR) nir/red $800 \mathrm{~nm} /$ $675 \mathrm{~nm}$. (Huete 1988)

- Simple ratio (SR) nir/red $800 \mathrm{~nm} / 675 \mathrm{~nm}$ (Birth \& McVey 1968). 


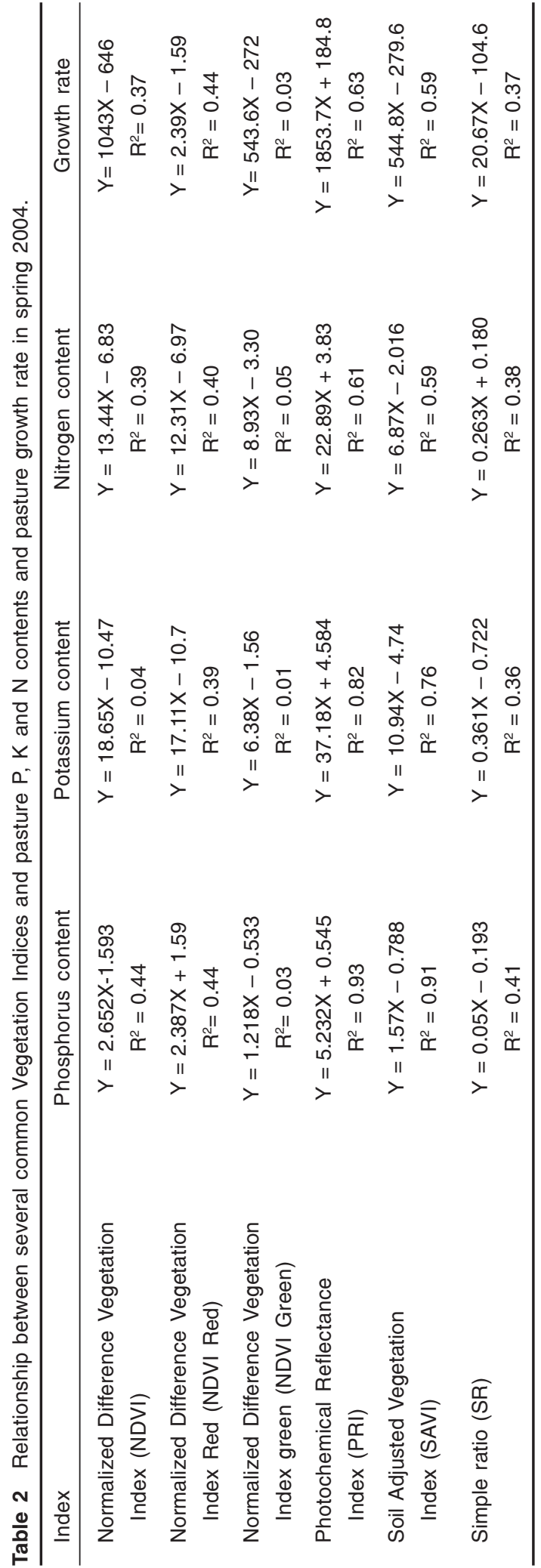

2. The normalized difference vegetation index (NDVI) was calculated for all available band combinations (bands 1 and 2) between 381 and $2214 \mathrm{~nm}$ to determine the best paired combination of bands for examining the relationship with pasture $\mathrm{P}$, for both the spring 2004 and summer 2006 data, to examine the relationships between years. The coefficients of determination $\left(\mathrm{R}^{2}\right)$ values were plotted in a matrix plot and the plot revealed a characteristic pattern with a number of "hot spots" having relatively high coefficients of determination. These spots were detected in each season by choosing the wavelength combinations that showed an $\mathrm{R}^{2}$ between $99.5 \%$ and $100 \%$ of the overall best index. The centre wavelength and bandwidth for each of the selected spots were determined by fitting a rectangle (see Fig. 2) that could hold the spot of interest inside its limits (Hansen \& Schjoerring 2003). The paired-bands which defined the zone of "hot spot" overlap (see Fig. 2) between 2004 and 2006 samplings identified the most robust NDVI model that was independent of both season and pasture condition.

The relationship between pasture $\mathrm{P}$ content and Olsen $\mathrm{P}$ for each year was also examined, with a logarithmic function giving a better fit than a simple linear regression.

\section{Results and Discussion}

Regression equations for the relationship between the vegetation indices calculated from spectra collected in spring 2004 and pasture $\mathrm{P}, \mathrm{K}$, and $\mathrm{N}$ content, dry matter content and pasture growth rate are listed in Table 2. Of the indices examined in this initial analysis, significant $(\mathrm{P}<0.05)$ relationships $\left(\mathrm{R}^{2}>0.90\right)$ were found between two of the indices (PRI and SAVI) and pasture P content. Less variation was accounted for with these two indices when examining their relationship with pasture $\mathrm{K}$ and $\mathrm{N}$ content or pasture growth rate (Table 2). All three NDVI indices had poor relationships with the plant attributes examined. None of the indices predicted pasture growth rate in spring 2004. The differences in the P content of pasture plants were consistent with the differences in soil $\mathrm{P}$ fertility, as indicated by the relationship between pasture $\mathrm{P}$ content from spring/summer in 2004/05 and soil Olsen P measured in the autumn of 2004 ( $\mathrm{Y}=$ $\left.0.117 \operatorname{Ln}(X)-0.072, R^{2}=0.90, P<0.05\right)$.

In a second analysis using all spectral data, the NDVIlike index was calculated for all available band combinations between 381 and $2214 \mathrm{~nm}$ to determine the best paired combination of bands for examining the relationship with pasture $\mathrm{P}$ for both spring 2004/05 and summer 2005/06. The results are presented in Figure 1. Of the normalized two-band indices, NDVI is the most widely used vegetation index, using the difference between high reflectance in the near-infrared (NIR) and 
Figure 1 Coefficient of determination $\left(R^{2}\right)$ from linear regressions of the normalized difference vegetation index (NDVI) against $\mathrm{P}$ content of pasture for all combinations of available bands between 350 and 2500 $\mathrm{nm}$, in both spring 2004 and summer 2006. Green zones indicate the band-pairs that best predict plant $\mathrm{P}$ content.

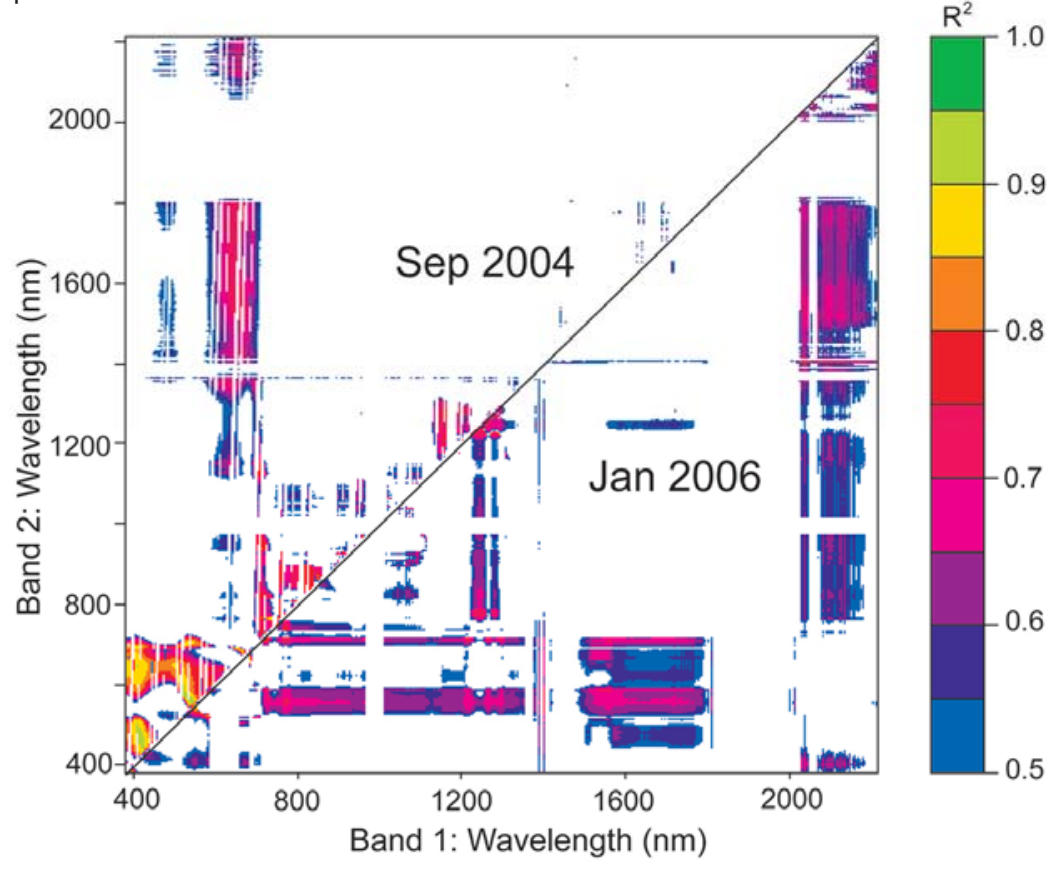

Figure 2 The "hot spot" areas in 2004 (blue), 2006 (green) and in both 2004 and 2006 (overlapped, red), defined as the top $0.5 \%$ of $\mathrm{R}^{2}$ values from all available waveband combinations against pasture $\mathrm{P}$ shown in Figure 1. Rectangles are centred on the centres of bands 1 and 2 (Table 3) and their extent shows the band width over which this relationship remains strong.

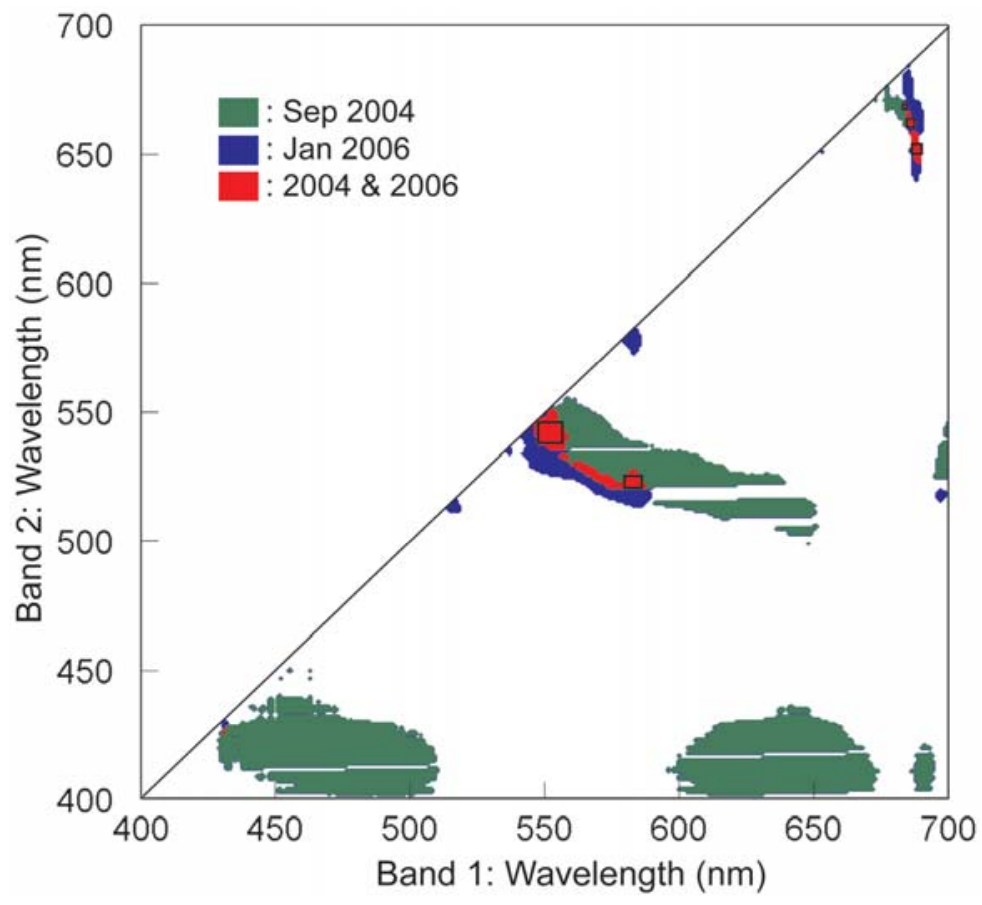


Table 3 The band centres and $\mathrm{R}^{2}$ values of best NDVI-like indices from the top $0.5 \%$ of all combinations.

\begin{tabular}{|c|c|c|c|c|c|}
\hline \multirow[b]{2}{*}{ Variable } & \multirow[b]{2}{*}{ Index ${ }^{1}$} & \multicolumn{2}{|c|}{ Band centres and widths $(\mathrm{nm})$} & \multicolumn{2}{|c|}{$\begin{array}{l}\text { Coefficient of } \\
\text { determination }\end{array}$} \\
\hline & & Band 1 centre $(\Delta \lambda 1)$ & Band 2 centre $(\Delta \lambda 2)$ & 2004 & 2006 \\
\hline \multirow[t]{5}{*}{ Pasture P (\%) } & 1 & $431(1)$ & $423(1)$ & $0.90^{* * *}$ & $0.72^{\star \star \star}$ \\
\hline & 2 & $583(4)$ & $523(4)$ & $0.92^{\star \star \star}$ & $0.83^{* * *}$ \\
\hline & 3 & $551(6)$ & $544(6)$ & $0.91^{\star \star \star}$ & $0.85^{\star \star \star}$ \\
\hline & 4 & $688(2)$ & $653(3)$ & $0.89^{\star \star \star}$ & $0.90^{\star \star \star}$ \\
\hline & 5 & $686(2)$ & $662(2)$ & $0.89^{\star \star *}$ & $0.88^{\star \star *}$ \\
\hline
\end{tabular}

The symbols $\Delta \lambda 1$ and $\Delta \lambda 2$ denote the bandwidths relative to the matching centre wavelength.

The highest value of $R^{2}$ in each year is shown in bold type.

${ }^{1}$ Except for Index 1 which is too small to see, these are depicted by black boxes in Figure 2. $\quad{ }^{* * *}: \mathrm{P}<0.001$

low reflectance in the red region of the electromagnetic spectrum to predict biophysical parameters. Several paired bands with high coefficients of determination $\left(\mathrm{R}^{2}\right)$ were detected with pasture P content (Fig. 2) suggesting a single spectral reflectance curve, taken by the hand held radiometer of pasture in situ, could be used to predict this plant parameter. Further, we found adjoining bands that had high $\mathrm{R}^{2}$ values that would shift the analysis from single band combinations to multiple band combinations that could be described as "hot spots" and the basis for sensing pasture P content (Table $3)$. This needs to be examined further, as do other methodologies for interpreting the spectral data.

With a good fit between plant P content in spring/ summer 2005/06 and soil Olsen P fertility in autumn $2005\left(\mathrm{Y}=0.0079 \operatorname{Ln}(\mathrm{X})+0.074, \mathrm{R}^{2}=0.86, \mathrm{P}<0.05\right)$, as well as in 2004, and when combined for the 2 years of data $\left(\mathrm{Y}=0.095 \operatorname{Ln}(\mathrm{X})+0.009, \mathrm{R}^{2}=0.83, \mathrm{P}<0.05\right)$, the approach offers scope for indirectly assessing soil $\mathrm{P}$ fertility. Olsen $\mathrm{P}$ is the most common soil test used for assessing the P fertility of New Zealand's grazed pastures. Using the optimal waveband pair from a single spectral reflectance curve of pasture taken in spring or summer to generate the NDVI-like value, we could detect differences in the $\mathrm{P}$ content of pasture plants that were consistent with the differences in soil P fertility measured by the Olsen P soil test, to the extent that areas of low (i.e. part of the response curve where pastures respond to added $\mathrm{P}$ ), moderate (i.e. optimum agronomic range) or high fertility (i.e. above optimum for plant growth and representative of an elevated environmental risk) could be identified and classified.

Interestingly, for both the spring 2004 and summer 2006 data sets, the paired-bands with high coefficients of determination $\left(\mathrm{R}^{2}\right)$ detected pasture $\mathrm{P}$ and $\mathrm{K}$ content, but not pasture growth rate, pasture dry matter content, or pasture $\mathrm{N}$ content. This suggests a single spectral reflectance curve taken by the hand-held radiometer of pasture in situ could be used to predict both plant $\mathrm{P}$ and K content.

The original intent of this pilot study was to repeat the sampling in spring 2005, to coincide with the spring 2004 sampling. However, because of cloud cover, the second sampling was delayed until January 2006. This highlights one of the difficulties of the technology which, in this experiment, was dependent on solar radiation as the light source.

The pasture $\mathrm{P}$ content $(0.15-0.42 \% \mathrm{P})$ and soil $\mathrm{P}$ status (Olsen P 6 - $68 \mu \mathrm{g} / \mathrm{ml}$ ) across the 30 plots used to examine the potential use of this technology for determining $\mathrm{P}$ content of plants as an indicator soil $\mathrm{P}$ fertility, covered both the very responsive part of pasture growth curve for this nutrient (Olsen P 6-30), and the asymptote (Olsen P 40-68). The pasture samples from the low fertility plots were clustered in the range 0.15 $0.22 \% \mathrm{P}$, whereas pastures from the high fertility plots formed a second cluster $(0.34-0.42 \% \mathrm{P})$. With the large number of samples used in this study, the relationship was not unduly influenced by any one data point. Future study will also include pastures that fall in the mid-range of soil fertility and will examine other pasture types (both species and morphologies) under different management systems and on a greater range of soils.

\section{Conclusions}

Significant relationships were found between two commonly used vegetation indices (PRI and SAVI) and pasture $\mathrm{P}$ content. These indices were poor predictors of pasture $\mathrm{K}$ and $\mathrm{N}$ content and of pasture growth rate. However, the exploratory analysis using all the spectral waveband data revealed several paired-bands, which used in an NDVI-like equation, gave high coefficients of determination that could be used to predict plant $\mathrm{P}$ and $\mathrm{K}$ content in both the spring and summer data sets. The differences detected in pasture $P$ content were consistent with the differences in soil P fertility measured by the Olsen $\mathrm{P}$ soil test.

We believe that imaging pastures with the selected paired-band combinations in the form of a vegetation index may enable the underlying soil P fertility to be classified as low (pasture responds to added P), moderate (optimum agronomic $\mathrm{P}$ response) or high 
(above optimum for plant growth; poses environmental risk). This pilot study will be broadened to examine other methodologies for interpreting the spectral data and extended to other pasture types and soil groups of varying soil fertility.

\section{ACKNOWLEDGEMENTS}

The authors would like to thank Roger Parfitt (Landcare Research) for access to the plots and data from the biodiversity study. This work was supported by funding from the FRST contract C02X0405 (Sustainable Land Use Research Initiative), ARC05031 (Satellites on farms) research programme and a Research Fellowships of Japan Society for the Promotion of Science (JSPS) for Young Scientist.

\section{REFERENCES}

Betteridge, K.; Schnug, E.; Haneklaus, S. 2006. Will site specific nutrient management live up to expectation? 14th World Fertiliser Congress, Chaing Mai, Thailand, Jan 22-30, 2006.

Birth, G.S.; McVey, G. 1968. Measuring the color of growing turf with a reflectance spectrophotometer. Agronomy Journal 60: 640-643.

Bredemeier, C.; Schmidhalter, U. 2005. Laser-induced chlorophyll fluorescence sensing to determine biomass and nitrogen uptake of winter wheat under controlled environment and field conditions. pp. 273280 In: Precision Agriculture '05. Ed. J.V. Stafford. Wageningen Academic Publishers, Wageningen, The Netherlands.

Coquil, B.; Bordes, J. P. 2005. FARMSTAR: an efficient decision support tool for near real time crop management from satellite images. pp. 873-880 In: Precision Livestock Farming '05. Wageningen Academic Publishers, Wageningen, The Netherlands.

Curran, P.J. 1989. Remote sensing of foliar chemistry. Remote Sensing of Environment. 30: 271-278.

Ferwerda, J.G.; Skidmore, A.K.; Mutanga, O. 2005. Nitrogen detection with hyperspectral normalised ratio indices across multiple plant species. International Journal of Remote Sensing 26: 4083-95

Florin. M.J.; McBratney, A.B.; Whelan, B.M. 2005. Extending site-specific crop management from individual fields to an entire farm. pp. 857-863 In: Precision Agriculture 2005. Ed. J.V. Stafford. Wageningen Academic Publishers, Wageningen, The Netherlands.
Gitelson, A.; Kaufman, Y.; Merzlyak, M. 1996. Use of a green channel in remote sensing of global vegetation from EOS-MODIS. Remote Sensing of Environment 58: 289-298.

Huete, A.R., 1988. A Soil Adjusted Vegetation Index (SAVI). Remote Sensing of Environment 25: 295309.

Lund, E.D.; Adamchuck, V.I.; Collings, K.L.; Drummond, P.E.; Christy, C.D. 2005. Development of soil $\mathrm{pH}$ and lime requirement maps using on-the-go soil sensors. pp. 457-464 In: Precision Agriculture '05. Ed. J.V. Stafford, Wageningen Academic Publishers, Wageningen, The Netherlands.

Mackay, A.D.; Lambert, M.G.; Barker D.J. 1999. Effect of intensification of livestock farming on the physical properties of a hill soil. pp. 311-316 In: Best soil management practices for production. Eds. L.D. Currie et al. Occasional Report No. 12, Fertiliser and Lime Research Centre, Massey University, Palmerston North.

Mutanga, O.; Skidmore, A.K.; Prins, H.H.T. 2004. Predicting in situ pasture quality in the Kruger National Park, South Africa, using continuumremoved absorption features. Remote Sensing of Environment 89: 393-408.

Myers, V.I.; Heilman, M.D.; Lyon, R.J.P.; Namken, L.N.; Simonett, D.; Thomas, J.R.; Wiegand, C.L.; Woolley, J.T. 1970. Soil, water, and plant relations. pp. 253-297 In: Remote Sensing with Special Reference to Agriculture and Forestry, National Academy of Sciences, Washington, DC.

Rouse, J.W.; Hass, R.H.; Shell, J.A.; Deering, D.W. 1974. Monitoring Vegetation Systems in the Great Plains with ERTS-1. pp 309-317. In: Proceedings 3rd Earth Resources Technology Satellite Symposium.

Sudholter, E.J.R.; de Smet, C.P.M.; Zuilhof, H. 2005. Field effect transistors in precision agriculture. pp. 23-30 In: Precision Agriculture '05. Ed J.V. Stafford, Wageningen Academic Publishers, Wageningen, The Netherlands.

Treitz, P.M.; Howarth, P.J. 1999. Hyperspectral remote sensing for estimating biophysical parameters of forest ecosystems. Progress in Physical Geography 23: 359-390.

Vickery P.J.; Hedges, D.A.; Duggin, M.J. 1990. Assessment of the fertiliser requirement of improved pasture from remote sensing information. Remote Sensing of Environment 9: 131-146. 